\title{
Fiscal Policy Rules in an Overlapping Generations Model with Endogenous Labour Supply*
}

\author{
Giovanni Ganelli ${ }^{\dagger}$ \\ Department of Economics and IIIS, Trinity College Dublin \\ This Version: September 2002
}

\begin{abstract}
A fiscal policy rule in which taxation is a function of existing government debt (a "wealth-tax") is usually believed to be effective in providing stability. Using a discrete-time version of Blanchard's overlapping generations model, extended to include money and an endogenous labour supply we show that, contrary to the intuition, a wealth tax might not be enough to ensure the existence of a unique, well defined, saddle-path equilibrium. We suggest that a government willing to run a positive and sustainable level of debt could use an alternative financing rule, imposing an additional tax component, that is a function of the difference between the real interest rate and the tax rate on wealth.
\end{abstract}

${ }^{*}$ I would like to thank Neil Rankin for very valuable comments. I also thank for comments Lei Zhang and participants in the Warwick Macroeconomics Workshop and in the Money, Macro and Finance 2001 (Queen's University Belfast) and Royal Economic Society 2002 (University of Warwick) Conferences. This work is part of a research network on 'The Analysis of International Capital Markets: Understanding Europe's Role in the Global Economy', funded by the European Commission under the Research Training Network Programme (Contract No. HPRN-CT-1999-00067).

${ }^{\dagger}$ Correspondig author: Giovanni Ganelli, Department of Economics, Trinity College Dublin, Dublin 2, IRELAND. Email: ganellig@tcd.ie. Homepage: http://www.econserv2.bess.tcd.ie/ganellig. Tel.: 353-16083044. Fax: 353-1-6772503. 
J.E.L. Classification: E62, H63.

Keywords: Fiscal Policy, Wealth Tax, Overlapping Generations, Stability. 


\section{Introduction}

The sustainability of fiscal policy is an issue that has interested economists at least since Keynes (1923) and Domar (1944). Christ (1979) studied the implications of different rules for stability, in an ad hoc Keynesian framework.

In more recent times, this interest has also been fostered by policy-related events. The high levels of public debts in several European countries, for example, have been the cause of great concern among policy makers and public opinion in relation to the constitution of the European Monetary Union (EMU). Expressions like unsustainability, instability and default risk have entered the day-to-day debate on economic policies. The fears related to growing debts have been translated in to the strict constraint imposed by the Maastricht Treaty and the Stability and Growth Pact. Outside the EMU, the UK government and the House of Commons approved, in 1998, the Finance Act and the Code for Fiscal Stability. These documents specify two key fiscal rules that have to be followed in policy making. The "golden rule" requires that, over the economic cycle, the Government will borrow only to invest and not to fund current spending, while the "sustainable investment rule" recommends that the public sector net debt to GDP ratio is kept over the economic cycle at a "stable and prudent level". In the US, proposals aimed at imposing constitutional constraints on the Federal Government borrowing capabilities have been recently put forward. A Balanced Budget Amendment was rejected by the Senate only by one vote both in 1995 and in 1997.

The above examples show that the sustainability of public finances is a topical issue. At the same time, some of the resolutions and proposals that emerged in the policy arena have been criticized for not being based on rigorous economic foundations. This suggests that more academic research aimed at investigating, both theoretically and empirically, the implications of fiscal policy rules for sustainability is highly desirable.

Blanchard et al. (1990), for example, construct short, medium and long-term indicators of sustainability. Their exercise, based on the idea that a sustainable policy is one that does not violate the intertemporal budget constraint, has the merit to acknowledge the 
importance of forward looking behaviour in affecting policy outcomes. This approach, however, can be criticized on the grounds of being mostly an accounting exercise, that heavily depends on how good the forecasts about future variables are.

In our opinion, there is a need to use modern, fully microfounded models to investigate which fiscal policy rules are "stable", in the sense that they are consistent with the existence of a well defined equilibrium and of a unique convergent path. The most natural candidates for this kind of analysis are models of overlapping generations, in which Ricardian equivalence is broken and the debt is allowed to have real effects. A contribution in this direction is the work by Rankin and Roffia (1999), that uses a Diamond (1965) type, two-period-lives model to investigate the existence of a maximum sustainable level of debt. The main question they want to address is whether there can occur "catastrophes", defined as situations in which a well-defined debt steady-state suddenly ceases to exist while other variables, like consumption and the capital stock, still lay in an economically feasible range of values. Because of their interest in catastrophes, they mostly concentrate on comparing various steady-states for constant levels of debt, and they do not conduct a comparative analysis of different fiscal policy rules.

In this paper, we aim at comparing the dynamic effects of different fiscal policy rules, including ones in which the level of debt is endogenous, rather than being fixed at some constant, exogenous level. To do this, we use a modified version of the perpetual youth model provided by Blanchard (1985), in which agents face in every period a positive probability of death. Our point of departure is the discrete time treatment of Blanchard's model provided by Frenkel and Razin (1996). In the original Blanchard framework, disposable income is either given or it follows an exogenously imposed declining path. ${ }^{1}$ In our model, by endogenising the labour supply, we take in to account the impact of the labour-leisure trade off decisions of agents. On the other hand, we assume that labour is the only factor of production. Since in Blanchard (1985) capital is endogenous, our contribution is orthogonal to his in this respect.

\footnotetext{
${ }^{1}$ Disposable income is endogenous in Blanchard's model (since the real wage is endogenous), but it is given to the agent himself.
} 
The model that we present is similar to others that have been recently developed in the literature. Leith and Wren-Lewis (2000), for example, use a perpetual youth model to study the interaction between monetary and fiscal policy. While they introduce nominal rigidities in the analysis, they retain the original assumption of an exogenous labour supply. Another similar model is developed by Heijdra and Ligthart (2000), whose focus is not on debt, but on comparing the macroeconomic effects of three different tax regimes (capital, labour income and consumption tax).

We conduct three policy experiments. For comparative purposes, we start by looking at the case in which the government is not allowed to use debt at all. We find that the introduction of a positive probability of death is not enough, by itself, to cause an effect of balanced budget expansions on the real interest rate. This policy, on the other hand, reduces both consumption and leisure. The overall welfare effect is therefore negative.

We then study a policy similar to the one considered by Blanchard (1985), in which a government is initially holding its debt constant, and subsequently decides to increase the level of debt to a new, higher, steady state. As government expenditure is constant, we are assuming that taxes adjust endogenously to meet the increased payments of interest. We show that, under our assumption, this policy raises the real interest rate.

We finally consider the case of a "weal th tax", in which taxation is an increasing function of government debt (that enters positively the wealth of agents). Contrary to what we could expect, making taxes an increasing function of existing debt does not automatically guarantees stability. The presence of a wealth tax might not be enough to ensure the existence of a unique, well-defined saddle path leading to the equilibrium. In this situation, it could be the case that a huge increase in the tax coefficient on debt is needed in order to have a saddle path solution. Such an increase, however, could be not easy to implement for the government, because of political pressures. We suggest an alternative rule that can yield the same outcome, in which the government drastically reduces the tax rate on debt but adds another tax component, that is a function of the difference between the real interest rate and the tax coefficient on debt wealth. Our intention here is not to suggest 
that such a rule would be optimal, but only to give some insights in to what policy could be followed by a government that is in a position of having to control is debt, but that is prevented from implementing more stringent policies because of some political reasons. We believe that this situation reflects the dilemma faced by some European governments in the early 1990s, that were in a situation of having to reduce drastically their debt, but could not rely on very large parliamentary majorities to undertake more structural policies, like heavy taxation of wealth or permanent cuts in government expenditure.

The paper is organized as follows. Section 2 introduces the model, section 3 analyzes some steady-state and dynamic properties in the case in which there is no public sector, that is nested in our more general specification. Sections 4 and 5 look at the effects of different policy rules, while Section 6 draws some conclusions.

\section{The Model}

\subsection{Private Agents}

We consider a closed economy. In every period each agent faces a constant probability of death $(1-q)$. We also assume no population growth. The size of the cohorts of agents born in every period is constant across time and can be normalized to 1 . The size of the world population is therefore constant as well and equal to $\sum_{a=0}^{\infty} q^{a}=\frac{1}{1-q}$. Only one good is produced in the economy. Agents gain utility from consumption, money balances and leisure. In what follows, we introduce the optimization problem of a representative agent of age $a$ at time $t$. Before proceeding with the illustration of the model, it is useful to clarify our terminology. We will call variables relating to an individual of age $a$ individual variables, while aggregate variables will be the one obtained aggregating across individuals of all the different ages, and per-capita variables will be aggregate variables divided by the size of the population.

The representative agent maximizes the expected utility function ${ }^{2}$

\footnotetext{
${ }^{2} C_{a+s-t, s}$ denotes consumption of an agent of age $a+s-t$ at time $s$. An analogous notation holds for
} 


$$
E\left(U_{t}\right)=\sum_{s=t}^{\infty}(\beta q)^{s-t}\left[\log \left(C_{a+s-t, s}\right)+\chi \log \frac{M_{a+s-t, s}}{P_{s}}+\psi \log \left(1-L_{a+s-t, s}\right)\right]
$$

Where all the parameters are positive, $0<\beta<1$ is the discount factor, $C, \frac{M}{P}$ and $L$ denote consumption, real balances and leisure respectively. Preferences are homothetic and separable in consumption, real balances and leisure. The endowment of time in each period is normalized to 1. $L_{a+s-t, s}$ is the quantity of labour supplied in every period, $\left(1-L_{a+s-t, s}\right)$ is leisure. A standard assumption in this framework is the existence of insurance companies. We assume that insurance companies pay a net premium of $\left(\frac{1-q}{q}\right)$ on the agent's financial wealth for each period of his life, while they encash the agent's financial wealth if the agent dies. ${ }^{3}$ Agents can hold financial wealth as real balances or as government debt. In addition, they supply labour and pay lumps-sum taxes. The representative agent's period $t$ budget constraint in real terms is, therefore ${ }^{4}$

$$
D_{a, t+1}+\frac{M_{a, t}}{P_{t}}+C_{a, t}=\frac{1}{q}\left[\frac{M_{a-1, t-1}}{P_{t}}+\left(1+r_{t}\right) D_{a-1, t}\right]+\frac{W_{a, t}}{P_{t}} L_{a, t}-\tau_{t}
$$

Where $D, W, r, \tau$ and $P$ denote respectively government debt, nominal wage, real interest rate, real lump-sum taxes and prices. The agent's maximization problem is also subject to a standard No-Ponzi Game condition. It can be shown that solving the agent's optimization problem, aggregating across ages and dividing by the population size we can derive the per-capita equations that we present in next sub-section.

Before presenting these equations, it is useful to specify the technology used by firms and the behavior of the government. In order to make aggregation possible, we assume that the agents supply their labour in a perfectly competitive market. For the same reason, the other variables.

${ }^{3}$ As agents die in each period with probability $q$, these arrangements ensure a safe return of 1 on money and of $\left(1+r_{t}\right)$ on debt.

${ }^{4}$ Note the different timing convention for money and assets. Money between periods $t-1$ and $t$ is denoted by $t-1$, while government liabilities between $t-1$ and $t$ are indexed by $t$. This timing convention is used, for example, by Obstfeld and Rogoff (1996, Ch. 10). 
we assume that the marginal productivity of labour is invariant across ages. Another simplifying assumption is that labour is the only factor of production, with constant returns. The technology used by firms is therefore

$$
Y_{t}=L_{t}
$$

Where $L_{t}$ is the quantity of labour used in the production process. Under these assumptions, from the profit maximization condition we obtain $\frac{W_{t}}{P_{t}}=1$ in every period $t$.

In this paper we abstract from utility enhancing government spending. The government therefore spends on public expenditure that does not affect private utility. Government expenditure and interest payments on outstanding debt can be financed by seigniorage, lump-sum taxes and issuing of new debt, according to the single-period budget constraint

$$
G_{t}+\left(1+r_{t}\right) D_{t}=\tau_{t}+\frac{\left(M_{t-} M_{t-1}\right)}{P_{t}}+D_{t+1}
$$

In addition to this, the government must also respect a No-Ponzi game condition. It is important to notice that, since the government has an infinite life horizon, the real interest

rate applied to $D_{t}$ in $(4)$ is $\left(1+r_{t}\right)$, as opposed to $\frac{\left(1+r_{t}\right)}{q}$ in the private agents' budget constraint.

\subsection{Per-Capita Variables}

All per-capita variables will be indexed by the superscript $P C$. It is also useful to define formally total wealth as the sum of financial and human wealth

$$
T W_{t}=\left(1+r_{t}\right)\left[\frac{1}{1+i_{t}} \frac{M_{a-1, t-1}}{P_{t-1}}+D_{a-1, t}\right]+H_{a, t}
$$

Where $H_{a, t}$ is human wealth, defined as:

$$
H_{a, t}=\sum_{s=t}^{\infty} \alpha_{s, t} q^{s-t}\left(\frac{W_{a+s-t, s}}{P_{s}}-\tau_{s}\right)
$$


Human wealth is defined as the present discounted value of potential gross earnings (that would be earned if the agent chose to consume no leisure), minus taxes. ${ }^{5}$

Per-capita consumption is given by

$$
C_{t}^{P C}=\sum_{a=0}^{\infty}(1-q) q^{a} C_{a, t}=\left(\frac{1-q \beta}{1+\chi+\psi}\right) T W_{t}^{P C}
$$

Where $(1-q) q^{a}$ is the proportion of agents of age $a$ in the world population. ${ }^{6}$ The other per-capita variables are

$$
\begin{gathered}
T W_{t}^{P C}=\sum_{a=0}^{\infty}(1-q) q^{a} T W_{t}=H_{t}^{P C}+\left(1+r_{t}\right)\left[\frac{1}{1+i_{t}} \frac{M_{t-1}^{P C}}{P_{t-1}}+D_{t}^{P C}\right] \\
H_{t}^{P C}=\sum_{a=0}^{\infty}(1-q) q^{a}\left\{\sum_{s=t}^{\infty} \alpha_{s, t} q^{s-t}\left(\frac{W_{s}}{P_{s}}-\tau_{s}\right)\right\}=\sum_{s=t}^{\infty} \alpha_{s, t} q^{s-t}\left(1-\tau_{s}\right) \\
M_{t-1}^{P C}=\sum_{a=0}^{\infty}(1-q) q^{a-1} M_{a-1, t-1} \\
D_{t}^{P C}=\sum_{a=0}^{\infty}(1-q) q^{a-1} D_{a-1, t}
\end{gathered}
$$

Notice that, in the aggregation of wealth, we have used the fact that both taxes and real wages are invariant across ages, and that real wages can be set to 1 with the special production function (3). As a consequence, per-capita human wealth is equal to individual wealth for each agent.

\footnotetext{
${ }^{5}$ Of course, as leisure provides utility, agents will not choose to supply a quantity 1 of work in each period as long as the parameter on leisure in the utility function is positive $(\psi>0)$.

${ }^{6}$ The size of each cohort of agents is normalized to 1 , and each agents has a probability of surviving in every period equal to $q$. For the law of large numbers, therefore, $q^{a}$ is the number of agents of each cohort that survive till the age $a$.
} 
Similarly, as prices and interest rates are independent of age, per-capita money demand is given by

$$
\frac{M_{t}^{P C}}{P_{t}}=\chi \frac{\left(1+i_{t+1}\right)}{i_{t+1}} C_{t}^{P C}
$$

The following per-capita labor-leisure equation can also be derived

$$
L_{t}^{P C}=\sum_{a=0}^{\infty}(1-q) q^{a} L_{a, t}=1-\psi(1-q) \sum_{a=0}^{\infty} q^{a} C_{a, t}=1-\psi C_{t}^{P C}
$$

The latter relationship is useful to illustrate an important characteristic of the model, namely the fact that private consumption and output (equal to the quantity of labour supplied) are determined by government expenditure. To show this, notice that in this simple closed economy, equilibrium in the goods market, in per-capita terms, boils down to

$$
Y_{t}^{P C}=L_{t}^{P C}=C_{t}^{P C}+G_{t}
$$

Solving for $L_{t}^{P C}$ and $C_{t}^{P C}$ from (9) and (10) we obtain:

$$
\begin{gathered}
Y_{t}^{P C}=L_{t}^{P C}=\frac{1}{1+\psi}+\frac{\psi}{1+\psi} G_{t} \\
C_{t}^{P C}=\frac{1}{1+\psi}-\frac{1}{1+\psi} G_{t}
\end{gathered}
$$

In the case in which leisure does not provide utility $(\psi=0)$, equations (11) and (12) reproduce the neo-classical result of no effect on output and complete crowding-out of consumption following a fiscal expansion $(d Y / d G=0, d C / d G=-1)$. In this case agents supply inelastically all their endowment of time. The balanced-budget multiplier derived in the IS/LM literature, $(d Y / d G=1, d C / d G=0)$, on the other hand, emerges in the limiting case in which $\psi \rightarrow \infty$.

While $Y_{t}^{P C}$ and $C_{t}^{P C}$ can be expressed as functions of an exogenous, predetermined variable like government expenditure, the real interest rate is a function of its future levels, behaving like a "jump" variable. In order to see this, it is useful to go through the intermediate step of characterizing the dynamic behavior of consumption. 


\section{$2.3 \quad$ Per-Capita Consumption Dynamics}

The dynamics of per-capita consumption is given by

$$
C_{t}^{P C}=\left(\frac{1-q \beta}{1+\chi+\psi}\right)(1-q) H_{t}^{P C}+\left(1+r_{t}\right) q \beta C_{t-1}^{P C}
$$

In the case of infinite life $(q=1)$ equation (13) reduces to a standard Euler equation. In that case human wealth is not relevant for predicting future consumption. The above expression also nests the logarithmic case in the Frenkel and Razin (1996) model, in which money and leisure do not provide utility $(\chi=\psi=0)$.

\section{Steady State and Dynamics without Government}

We will now characterize the steady-state and the dynamics of the model. It is convenient to consider first the case in which government expenditure, taxes and debt are permanently fixed to zero. As the model displays multiple equilibria, one issue that arises is how to discriminate between them. The preliminary analysis of this section gives some insights about this, that will also turn out to be useful once we reintroduce the government in the model.

\subsection{Steady State}

In an economy without public sector, consumption and output are permanently fixed at the "natural" level $\frac{1}{1+\psi}$. It follows that a steady-state version of equation (13) is ${ }^{7}$

$$
1+\bar{r}=1-(1+\psi)\left(\frac{1-q \beta}{1+\chi+\psi}\right)(1-q) \bar{H}^{P C}
$$

Where $\bar{H}^{P C}$ is the steady-state level of human wealth with $\tau=0$, i.e.

$$
\bar{H}^{P C}=\sum_{s=t}^{\infty}\left(\frac{q}{1+\bar{r}}\right)^{s-t}=\frac{1+\bar{r}}{1+\bar{r}-q}
$$

\footnotetext{
${ }^{7}$ Barred variables denote the steady-state.
} 


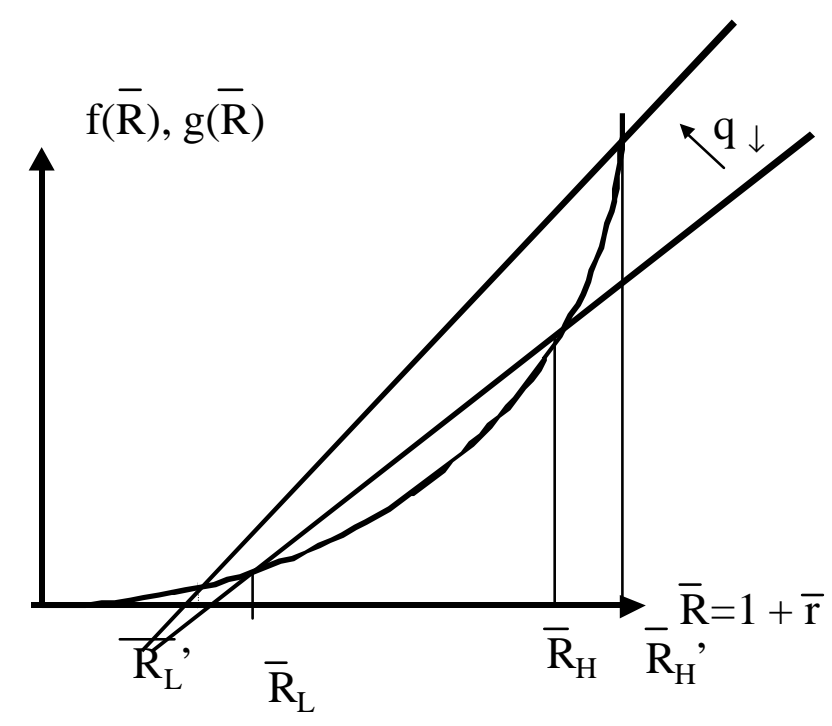

Figure 1:

Substituting (15) in (14) and denoting with $\bar{R}=1+\bar{r}$ the gross real interest rate we can derive the following quadratic equation in $\bar{R}$

$$
\bar{R}^{2}-\left\{q+\frac{1}{q \beta}\left[1-\left(\frac{1-q \beta}{1+\chi+\psi}\right)(1-q)(1+\psi)\right]\right\} \bar{R}+\frac{1}{\beta}=0
$$

To solve explicitly for $\bar{R}$ from this equation would be possible, but not very illuminating. The implications of (16) are more easily understood looking at Figure 1.

The two solutions of (16) are the points in which the parabola $f(\bar{R})=\bar{R}^{2}$ meets the line $g(\bar{R})=\left\{q+\frac{1}{q \beta}\left[1-\left(\frac{1-q \beta}{1+\chi+\psi}\right)(1-q)(1+\psi)\right]\right\} \bar{R}-\frac{1}{\beta}$. Given the ranges of values of the parameters, the slope of this line is obviously positive. From Figure 1 it is clear that we are faced with two possible equilibria. As the real interest rate is expected to behave like a jump variable, one way of discriminating between them is to select the unstable one. This can only be done after characterizing the dynamics of $R$. However, we can discriminate between the two different steady-states even before looking at the dynamics, if we assume that deviations from the Ricardian equivalence case $(q=1)$, are not too large. In particular, we can notice that, when Ricardian equivalence holds $(q=1)$, equation $(16)$ 
yields the two solutions $\bar{R}_{L}=1$ and $\bar{R}_{H}=\frac{1}{\beta} \cdot{ }^{8}$ In this case only the higher equilibrium is a well defined steady-state. This can be seen considering that, since there is no inflation in the steady state, $\bar{R}=1$ implies $\bar{r}=\bar{i}=0$, i.e. an infinite money demand. In addition, it is clear from equation (15) that $\bar{R}=1$ also implies an infinite level of steady-state human wealth. Furthermore, considering that the derivative of $\left\{q+\frac{1}{q \beta}\left[1-\left(\frac{1-q \beta}{1+\chi+\psi}\right)(1-q)(1+\psi)\right]\right\}$ computed at $q=1$, being equal to $\frac{\beta-1}{\beta}\left(\frac{\chi}{1+\chi+\psi}\right)$, is negative, in the neighborhoods of this value a fall in $q$ implies an increase of the "higher" equilibrium (that is a movement from $\bar{R}_{H}$ to $\bar{R}_{H}^{\prime}$ in Figure 1 ) and a fall of the "lower" equilibrium (from $\bar{R}_{L}$ to $\bar{R}_{L}^{\prime}$ in Figure 1 ). It follows that, if the deviation from the infinite life case is not too big (if $q$ is not too much smaller than 1), we are sure that $\bar{R}_{L}$ becomes smaller than one. Since in a zero inflation steady-state nominal and real interest rate coincide, $\bar{R}_{L}$ implies a negative nominal interest and cannot be considered a well-defined steady-state.

As we are going to show in what follows, the analysis of the dynamics of the model will lead to the same conclusion. In particular, it will allow us to prove that, even for large deviations from Ricardian equivalence, reducing $q$ rises (lowers) the higher (lower) equilibrium. This conclusion will give more generality to the arguments developed above.

\subsection{Dynamics}

In this simplified version, the dynamics of the model can be summarized by a first-order non-linear difference equation for the gross real interest rate, given by

$$
R_{t+1}=\frac{1}{\frac{1}{q}\left[1-(1+\psi) \frac{(1-q \beta)}{(1+\chi+\psi)}(1-q)\right]+q \beta-\beta R_{t}}
$$

Equation (17) reduces to the quadratic expression that characterizes the steady state if we impose $R_{t}=R_{t+1}=\bar{R}$. The dynamics out of the steady state can be investigated with the help of Figure 2, where we plot equation (17) together with the $R_{t}=R_{t+1}$ line.

\footnotetext{
${ }^{8}$ Notice that, when agents have infinite lives, our model collapses to a discrete time version of the Ramsey (1928) model. When $q=1$, equation (16) yields the two solutions $\bar{R}_{L}=1$ and $\bar{R}_{H}=\frac{1}{\beta} \cdot \bar{R}_{H}=\frac{1}{\beta}$ is the solution of the Ramsey model, while $R_{L}=1$ is not.
} 


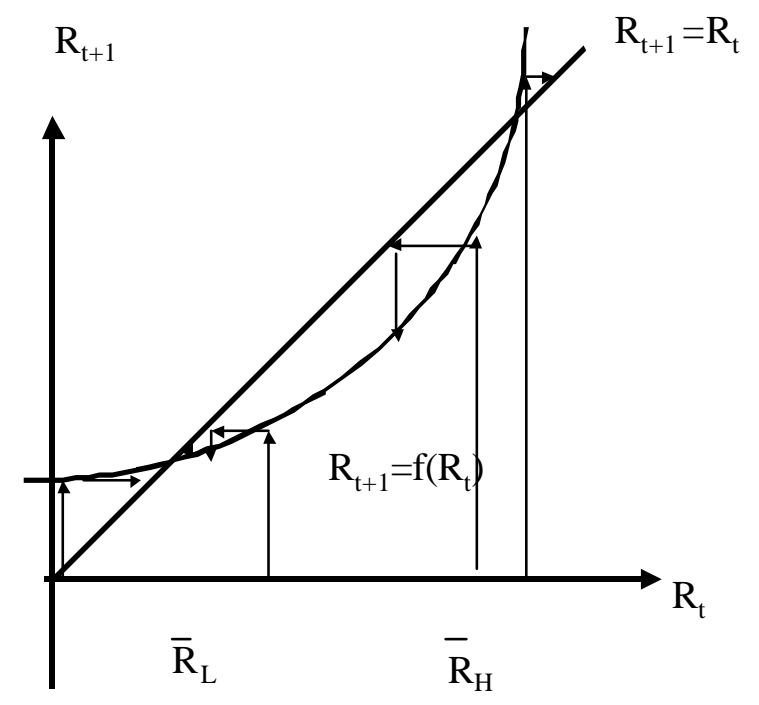

Figure 2:

Equation (17) is a hyperbola, that cuts the $R_{t}=0$ axis at $\frac{1}{\frac{1}{q}\left[1-(1+\psi) \frac{(1-q \beta)}{(1+\chi+\psi)}(1-q)\right]}$.

We can restrict our attention to the positive arm, that tends to the vertical asymptote $R_{t}=\frac{\frac{1}{q}\left[1-(1+\psi) \frac{(1-q \beta)}{(1+\chi+\psi)}(1-q)\right]}{\beta}$ as $R_{t+1} \rightarrow \infty$.

From equation (17) it is evident that, starting form every point on the left or on the right of $\bar{R}_{L}$, the economy will converge back to $\bar{R}_{L}$, while the opposite happens around $\bar{R}_{H}$. Therefore, $\bar{R}_{H}$ is the unstable equilibrium. As this is a forward-looking, rationalexpectations model, this property should not be regarded as problematic. On the contrary, it is a very desirable feature. The logic of the rational expectations method is that, if there is a unique possibility that ensures boundedness, this is the one that will be selected. In other words, the real interest rate acts as a jump variable, making the model "well behaved" in terms of dynamics. This confirms that, in what follows, we can restrict our attention on $\bar{R}_{H}$

From Figure 2 is also possible to derive an analysis of the effects of the probability of death on the real interest rate that is not limited to the case in which the value of $q$ lies in the 
vicinity of 1 . It is possible, infact, to show that the derivative of $\frac{1}{q}\left[1-(1+\psi) \frac{(1-q \beta)}{(1+\chi+\psi)}(1-\right.$ $q)]+q \beta$ with respect to $q$ is equal to $\frac{\left(q^{2} \beta-1\right)}{q^{2}} \frac{\chi}{(1+\chi+\psi)}$, that is unambiguously negative. This implies that a decrease in $q$, by raising the denominator of (17), will shift the hyperbola downward, thus raising $\bar{R}_{H}$ and lowering $\bar{R}_{L}$. In the unstable steady-state, an increase in the temporal horizon of agents decreases the real interest rate. This confirms that the unstable steady-state is the one that yields the more sensible result in terms of comparative static, even if deviations from Ricardian equivalence are large (if $q$ is considerably smaller than 1 ). Furthermore, the above result show that, if we start from the Ricardian case $(q=1)$ and we reduce the probability of survival, the gross real interest rate in the lower equilibrium becomes smaller than 1. Again, the lower equilibrium implies a negative nominal interest rate and cannot be considered a well defined steady state. Unlike in the previous subsection, the result derived here proves that this is the outcome even if the reduction from $q=1$ is not marginal.

As we are going to see in what follows, when we reintroduce the public sector in the model we can use similar arguments to discriminate between equilibria. The conclusions drawn from this simple version of the model are consistent with the more general case.

\section{Effects of Fiscal Policy}

We will now reintroduce the government in the model. In the policy rules studied in this section government debt is either not allowed or exogenous. The analysis of cases in which debt is endogenous is carried out in next section.

In the first policy experiment we look at a balanced budget expansion $(\bar{G}=\bar{\tau}, \bar{D}=0)$. In the second one we consider the steady-state effects of increasing debt from a constant level to another constant level. In the latter case, government expenditure is kept constant and taxes are assumed to adjust endogenously. As the focus is on fiscal policy, in both cases we hold the money supply permanently fixed at a constant level $\bar{M}$, ruling out seigniorage. For the reasons explained above we restrict our attention to the higher equilibrium $\bar{R}_{H}$. 


\subsection{Balanced-Budget Expansions}

We start considering the case in which the government is allowed to spend but not to use debt. Assuming a constant level of expenditure perfectly matched by lump-sum taxes in every period, the steady state of human wealth becomes: $\bar{H}^{P C}=\sum_{s=t}^{\infty}\left(\frac{q}{1+\bar{r}}\right)^{s-t}(1-\bar{\tau})=$ $(1-\bar{\tau}) \frac{1+\bar{r}}{1+\bar{r}-q}$. We can therefore derive a modified version of equation (16):

$$
\bar{R}^{2}=\left\{q-\frac{1}{q \beta}\left[1-\frac{(1-\bar{\tau})}{(1-\bar{G})}\left(\frac{1-q \beta}{1+\chi+\psi}\right)(1-q)(1+\psi)\right]\right\} \bar{R}-\frac{1}{\beta}
$$

Under a policy regime in which $\bar{G}=\bar{\tau}$, the above equation reduces to (16). This implies a quite unexpected result. Although our model is based on some "non neo-classical" assumptions, like the deviation from Ricardian Equivalence, balanced-budget fiscal expansions turn out not to affect the real interest rate. In Blanchard (1985), the real interest rate is equated to the marginal productivity of capital. As a balanced-budget expansion decreases capital in his model, the real interest rate increases. The assumption that labour is the only factor of production implies that, even with finite horizons, following a balancedbudget expansion our model behaves like the Ramsey one, in which the real interest rate is independent of movement in $G$, rather than like Blanchard's.

As in the steady state inflation is zero, nominal and real interest rates coincide. This implies no direct effect via the interest rate on real balances. Remembering equations (11) and (12), it is clear that, following a once and for all fiscal expansion, there will be a step increase in the quantity of labour supplied and a step decrease in consumption. Both consumption and leisure fall. ${ }^{9}$ Money demand, being a function of consumption, falls as well. The overall welfare effect of a balanced-budget fiscal expansion is therefore negative.

The welfare results of our model are qualitatively the same that can be derived, for the long run, in a closed-economy version of the Redux model presented by Obstfeld and Rogoff $(1995,1996) .{ }^{10}$ In the present model and in the Obstfeld and Rogoff model the

\footnotetext{
${ }^{9}$ The reduction in steady-state consumption in our model is consistent with both the Ramsey and Blanchard models.

${ }^{10}$ As the present model is a flexible-prices one, it would not be appropriate to compare our results with
} 
output multiplier is positive and the consumption multiplier is negative, and both are less than one in absolute value. If we assume $\psi<1$, the negative welfare effect is mitigated in our case, compared to the Obstfeld and Rogoff model. When $\psi=1$ our model and the closed-economy version of the Obstfeld and Rogoff model coincide.

A paper that looks at the consequences of a balanced-budget expansion in a sticky-price, continuous-time, perpetual-youth model with capital accumulation is Rankin and Scalera (1995). Their results are quite different from ours. In their model the long-run consumption multiplier is positive and the output multiplier is above unity. The authors explain this as a consequence of the fact that they have investment and capital accumulation. With no capital accumulation, their model would give the usual Keynesian balanced-budget multiplier $(d Y / d G=1, d C / d G=0)$. As we have already stressed in section 2.2 , this result only emerges here in the extreme case of an infinite weight of leisure in agents' preferences. The presence of an endogenous labour supply in our model is sufficient to deviate from the neo-classical result of a zero output multiplier, even in a flexible price world, but is not enough to generate the polar result of Rankin and Scalera (1995).

\subsection{The Case of Constant Debt}

We now turn our attention to another policy, in which the debt is fixed exogenously. We will therefore look at the steady-state effect of an increase from one constant level of $\bar{D}$ to a new constant level. From the government budget constraint with constant $\bar{G}, \bar{D}$ and $\bar{M}$, we have:

$$
\tau_{t}=\bar{G}+r_{t} \bar{D}
$$

When the government decides to raise the level of steady-state debt, $\bar{G}$ is kept constant, and taxes adjust endogenously to meet the increased interest payments.

The steady-state value of human wealth is now $\bar{H}^{P C}=\sum_{s=t}^{\infty}\left(\frac{q}{1+\bar{r}}\right)^{s-t}(1-\bar{G}-\bar{r} \bar{D})=$ $\frac{1+\bar{r}}{1+\bar{r}-q}(1-\bar{G}-\bar{r} \bar{D})$, and the steady-state equation for $R$ can be expressed as the short-run ones in Obstfeld and Rogoff $(1995,1996)$, where prices are sticky. 


$$
\begin{aligned}
\bar{R}^{2}= & \frac{\left[\frac{(1+\psi)(1-q)(1-q \beta)}{(1+\chi+\psi)(1-\bar{G})} \bar{D}+\frac{(1+\psi)(1-q)(1-q \beta)}{(1+\chi+\psi)}-q^{2} \beta-1\right]}{\frac{(1+\psi)(1-q)(1-q \beta)}{(1+\chi+\psi)(1-\bar{G})}-q \beta} R+ \\
& +\frac{q}{\frac{(1+\psi)(1-q)(1-q \beta)}{(1+\chi+\psi)(1-G)} \bar{D}-q \beta}
\end{aligned}
$$

The latter expression shows how the analysis becomes more complicated, compared to the previous cases considered in the paper. We will here present some analytical results on the effects of an increase in debt on the real interest rate in a particular case, that we label the "reference case".11

In our reference case steady-state debt is initially set to zero $(\bar{D}=0)$ and the utility provided by money is also zero $(\chi=0)$. A case in which initial steady-state debt is fixed to zero is quite a natural one to study, since it is continuous with the no-debt cases previously considered. As we already know, in the reference case the two steady-state solutions for $R$ are $\bar{R}_{L}=1$ and $\bar{R}_{H}=\frac{1}{\beta}$. Let's now notice that equation (19) can be rewritten as

$$
(q \beta-k \bar{D}) \bar{R}^{2}-\left[1+q^{2} \beta-(1-\bar{G}) k-k \bar{D}\right] \bar{R}+q=0
$$

where $k=\frac{(1+\psi)(1-q)(1-q \beta)}{(1+\chi+\psi)(1-\bar{G})}$. Totally differentiating and evaluating in the reference case we have

$$
[q \beta 2 \bar{R}-(q+q \beta)] d \bar{R}+\left(-k \bar{R}^{2}+k \bar{R}\right) d \bar{D}
$$

Further, evaluating at the higher steady-state $\bar{R}_{H}=\frac{1}{\beta}$ and rearranging we have

$$
\frac{d \bar{R}}{d \bar{D}}=\frac{k}{\beta q^{2}}
$$

that proves the positive effect of an increase in debt on the real interest rate in the reference case.

\footnotetext{
${ }^{11} \mathrm{~A}$ more general discussion, not reported here for the sake of brevity, can be found in a longer version of the paper available from the author's homepage: http://econserv2.bess.tcd.ie/ganellig/fis_rules.pdf. The results presented there confirms that those derived for the "reference case" are the most likely to emerge.
} 
If, as the analysis of the reference case suggests, an increase in the exogenous level of debt increases the steady-state level of the interest rate, then this policy has two negative welfare effects. The first one arises through real balances. Since in the steady state nominal and real interest rate coincide, an increase in $\bar{R}_{H}$ implies that agents demand less money, and this reduces their utility. The second effect is due to the fact that an increase in the real interest rate implies an higher growth rate of consumption over an individual's lifetime. Since average lifetime consumption does not change (the level of per-capita consumption does not change, see equation 12), this effect increases the imbalance in the lifetime consumption profile. We could expect, on an intuitive basis, that this would further reduce lifetime utility.

In Blanchard (1985, p.243), a similar policy reduces the steady-state levels of both capital and consumption. In his model, therefore, the real interest rate increases unambiguously. This is what is likely to happen in our model. In our model, however, we have no effect on per-capita consumption. This difference is due to the fact that, keeping the level of capital constant, we have prevented movements in the real interest rate from having direct effects on consumption. In Blanchard, the decrease in capital associated with an increase in $R$ has a direct, negative effect on consumption. This does not happen in our model, because capital does not change.

\section{Introduction of a Wealth Tax}

In the policy experiments considered so far, government debt was either zero or fixed at a constant level exogenously determined. We now turn to the case in which taxes are a function of the existing level of debt. In this case both debt and taxes are endogenously determined.

Since government debt enters as an asset in the portfolio of agents, we refer to this as a "wealth tax". It is important to stress, however, that this kind of instrument, being a function of per-capita debt, should not be regarded as a wealth tax in the strictest sense, i.e. one that distorts agents' decision. From an individual's point of view, the tax is a 
"lump-sum" one. The size of the lump-sum depends on aggregate wealth, but a single individual has no influence on the latter. Examples of taxation imposed on aggregate wealth, without distortionary consequences, can be found both in the theoretical literature (for example Rankin and Scalera, 1995) and in large-scale macroeconometric models used for policy simulations (Mitchell et al. 1999).

Formally, the rule that we are considering, is expressed as

$$
\tau_{t}=T+\tau D_{t}
$$

for every $t$, with $0<\tau<1$ and $G>T$. On an intuitive basis, we would expect that if the real interest rate is smaller than the rate at which new debt feeds in to new taxes $\left(\tau>r_{t}\right)$, this rule should grant stability, preventing the debt from exploding (see below, equation 20).

The most interesting result in this section is that, contrary to the intuition, we can not rule out cases in which this rule fails, for realistic parameters values, to ensure the existence of a well-defined equilibrium with a unique convergent path. If $R_{t}$, as it appears in equation (20) below, was independent of debt (as it is the case in the Ramsey model), then stability would depend only on the sign of $r_{t}-\tau_{t}$. If we get instability, then, it must be because of the dynamics in $R_{t}$, which are introduced by the fact that, when $q<1, R_{t}$ depends on $D_{t}$. This means that an overlapping generations economy is more likely to be unstable, under a given wealth tax rule, than a Ramsey economy. Failing to consider the implications of finite horizons implies that rules similar to the one that we are analysing are usually believed, especially in policy related analysis, to be effective in "closing" the model. Mitchell et al. (1999, pag. 171), for instance, in comparing the properties of different macroeconometric models, refer to "The specification of a fiscal policy reaction function or fiscal closure rule that enforces the government's intertemporal budget constraint...". In their analysis, based on an infinite horizons theoretical framework, a tax rule that makes taxation a function of the existing stock of debt ensures convergence of debt (in the case of no real growth) if $\tau$ ( $\theta$ in their notation) is bigger than the (exogenous) real interest rate (Mitchell et al. 1999, pag. 179). 
The implications of such a rule in our model are investigated in what follows using a combination of graphical analysis and numerical simulations. The dynamics of the economy can be summarized by the following two non-linear difference equations in $R_{t}$ and $D_{t}$.

$$
\begin{gathered}
D_{t+1}=\left(R_{t}-\tau\right) D_{t}+\bar{G}-T \\
R_{t+1}=\frac{1}{-\left(1-\tau D_{t}-T\right) \frac{(1+\psi)}{(1-\bar{G})} \frac{(1-q \beta)}{(1+\chi+\psi)} \frac{(1-q)}{q}+q \beta+\frac{1}{q}-\beta R_{t}}
\end{gathered}
$$

Equation (20) comes from substituting the tax-rule in to the period by period government budget constraint with constant $\bar{G}$, and $\bar{M}$, while (21) is the expression equivalent to (17), once we take into account that now $H_{t}^{P C}=\sum_{s=t}^{\infty} \alpha_{s, t} q^{s-t}\left(1-\tau_{s}\right)=\sum_{s=t}^{\infty} \alpha_{s, t} q^{s-t}(1-T-$ $\left.\tau D_{s}\right)$.

The locus $\Delta D_{t}=0$ is a hyperbola with intercept $D_{t}=\frac{\bar{G}-T}{\tau+1}$, and $R_{t}=\tau+1$ and $D_{t}=0$ respectively as vertical and horizontal asymptotes. Debt converges back to the locus on the left of the vertical asymptote (where $\tau>r$ ), and diverges away from it on the right (where $r>\tau$ ). The locus $\Delta R_{t}=0$ is the sum of a straight line with positive slope and of a hyperbola. It tends to the straight line as $R_{t} \rightarrow \infty$ and to the hyperbola as $R_{t}$ $\rightarrow 0$. $R_{t}$ decreases above the locus and increases below.

In principle, the existence of steady-state solutions could be studied analytically, imposing constant levels of $D$ and $R$ in equations (20) and (21) and solving the system. Doing this without assigning specific parameters to the values would not allow us to derive neat expression for the solutions. Before resorting to simulations, however, it is useful to stress that, combining equations (20) and (21), it is possible to show that the steady-state values are the solutions of a cubic equation, that therefore has either one or three real roots. All the possible cases are presented graphically in Figures 3 to $5 .{ }^{12}$ The three possible steady states are labelled, starting with the lower, as $\bar{R}_{1}, \bar{R}_{2}$ and $\bar{R}_{3}$. If there is only one solution,

\footnotetext{
${ }^{12}$ The practice of drawing phase dyagrams for discrete systems is a standard one in modern macroeconomics (see, for example, Blanchard and Fischer, 1989, pp. 230-31).
} 


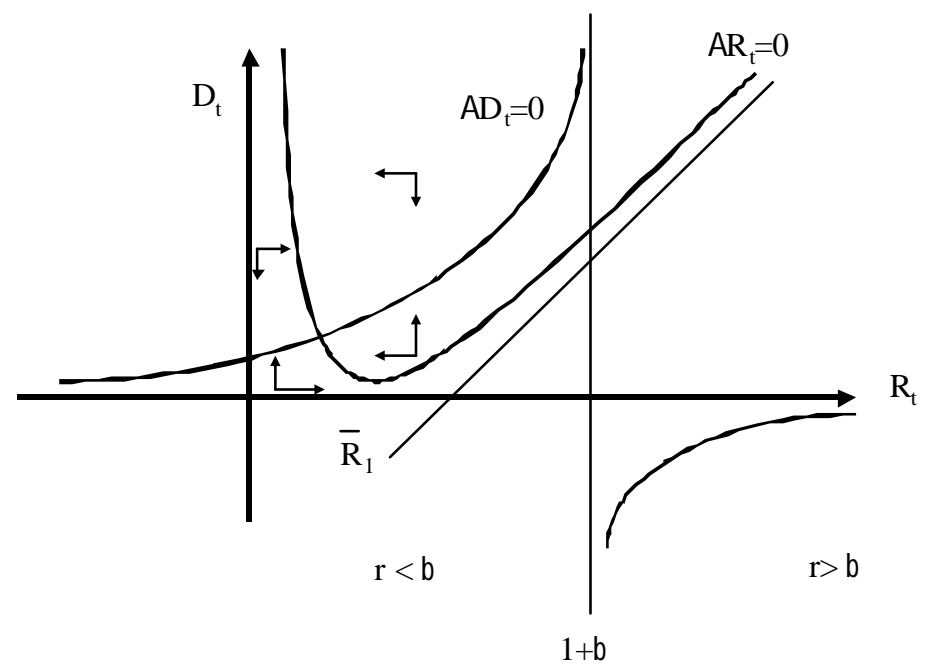

Figure 3:

this can only be in the region where $r<\tau$ (Fig. 3). The case of three solutions can happen in two different ways: all the solutions where $r<\tau$ (Fig. 4), or one where $r<\tau$ and two where $r>\tau$ (Fig. 5).

It is evident that steady-states in the region where $r>\tau$ can only occur for negative values of debt. The intuition behind this is that when the real interest rate is bigger than the taxation coefficient, existing debt generates new debt at a faster rate than it increases taxation. As a result, it is only possible to have a stable level of debt if this is negative, i.e. if agents are borrowing from the government. In this case an increase in $r$ is good news for the government's finance. We are induced to pay little attention to the possibility of such an outcome, however, on the basis of the observation that equilibria with negative values of government debt are not very likely in reality. On the normative side, we are interested in sustainability, so we do not want to suggest a rule that would eliminate government debt completely. ${ }^{13}$

What about the region in which $r<\tau$ ? From Figures 3, 4 and 5 it is clear that the

\footnotetext{
${ }^{13}$ A positive level of debt can be a desirable property of an economy, as long as it is sustainable. In our model, for instance, debt facilitates consumption smoothing over time.
} 


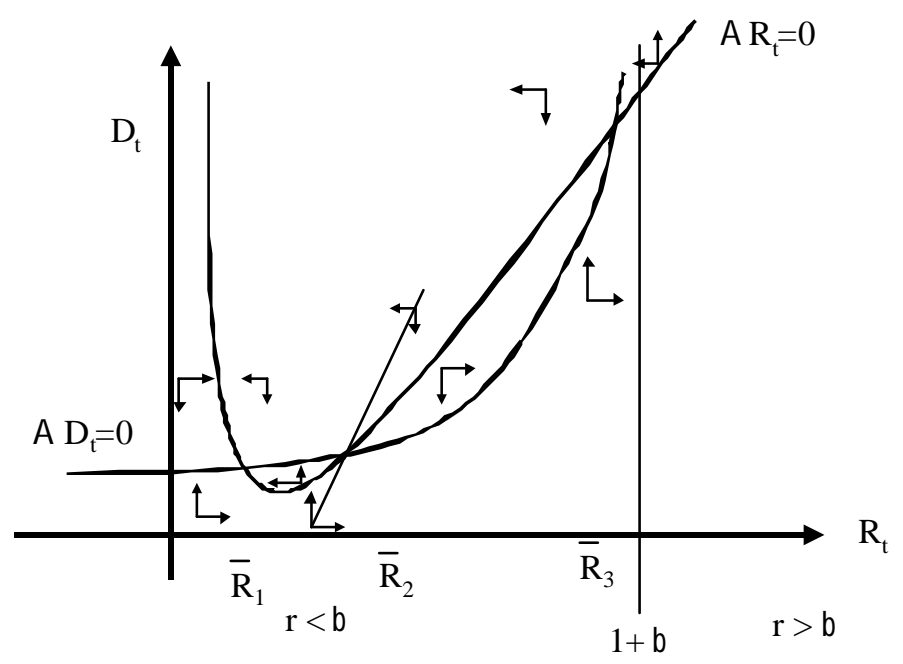

Figure 4:

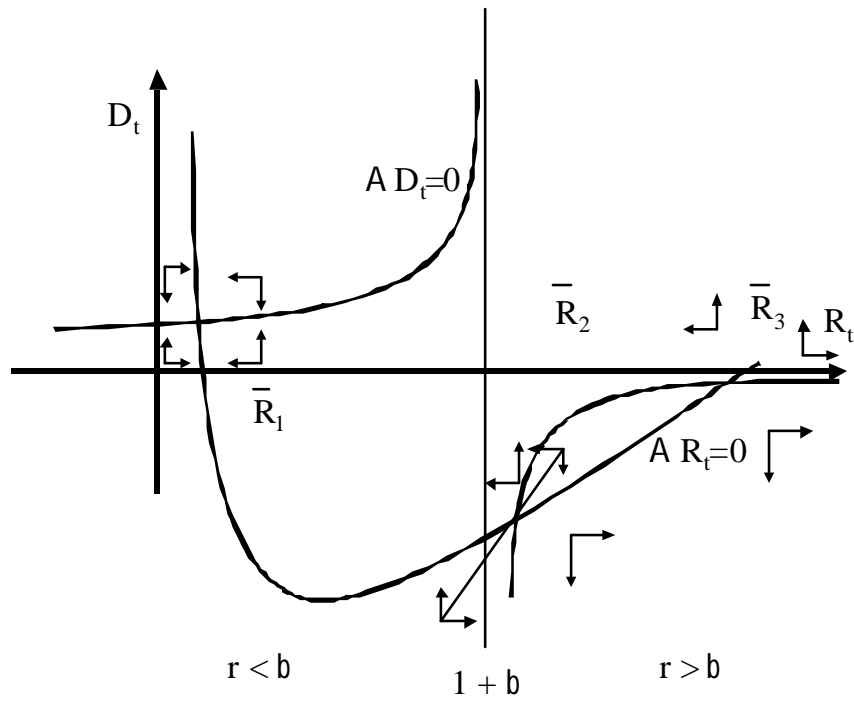

Figure 5: 


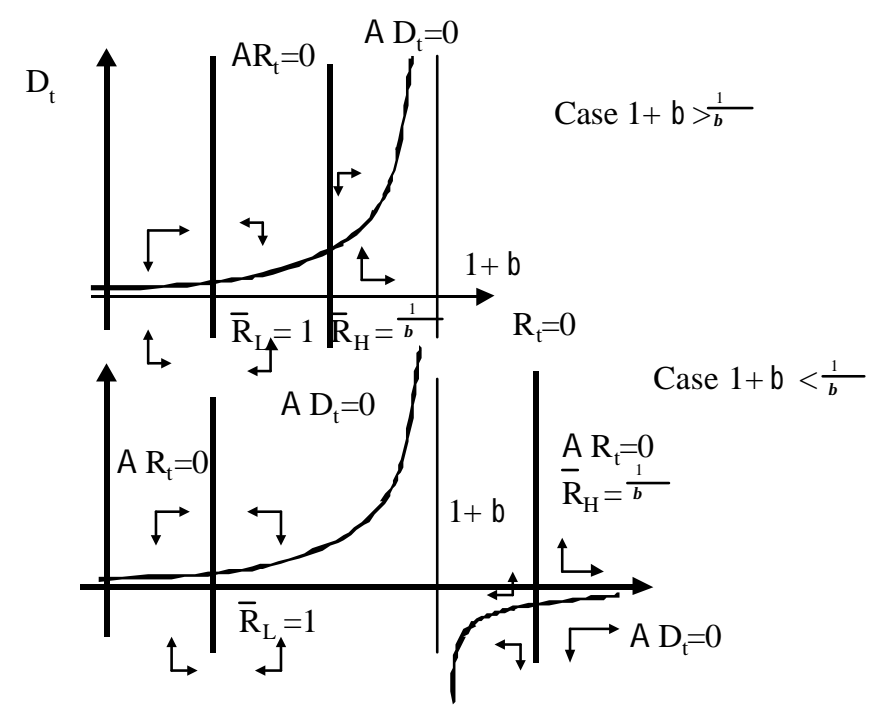

Figure 6:

steady-state $\bar{R}_{1}$ in this region is globally stable. However, we are quite doubtful about the practical relevance of this equilibrium, for several reasons. The first one is that it implies a multiplicity problem, i.e. there is no unique path along which the system converges. It is also possible to show that, as in the previous cases, this lower equilibrium is not a well defined steady-state because it implies a negative nominal interest rate. In order to show this, we start considering the case in which Ricardian equivalence holds $(q=1)$. This yields a discrete-time version of the Ramsey model with a wealth tax. In this situation, debt financing becomes irrelevant for the real interest rate, and the solutions for $\bar{R}$ are only two, and they are equivalent to the ones that we obtain when there is no government in the model: $\bar{R}_{L}=1$ and $\bar{R}_{H}=\frac{1}{\beta}$. The $\Delta R=0$ locus collapses to two vertical lines in correspondence of the two solutions for $R$. Figure 6 describes the dynamics in this case.

It is clear that the $\bar{R}_{L}$ is always a sink, whereas $\bar{R}_{H}$ implies a positive (negative) debt and is a saddle (source) if $1+\tau>\frac{1}{\beta}\left(1+\tau<\frac{1}{\beta}\right)$. The equilibrium $\bar{R}_{H}$ with $1+\tau>\frac{1}{\beta}$ is therefore the one that yields the case that we consider more satisfactory in terms of the stability properties, i.e. the saddle path. Comparing Figure 6 with Figure 3, 4 and 5 we can develop our argument to rule out $\bar{R}_{1}$. In Figure 6 , where $q=1$, the lower equilibrium 
yields a value of 1 for the gross real interest rate. Figures 3,4 and 5, however, suggest that when we marginally reduce $q$ from 1 to a value less than 1 , the $\Delta R_{t}=0$ locus goes from a straight to an hyperbolic shape. This implies that the $\bar{R}_{L}$ steady-state goes from 1 to a value smaller than 1 , becoming what we have denoted as $\bar{R}_{1}$ in figures 3 , 4, and 5. As already stressed, a gross real interest rate smaller than 1 , means $\bar{r}<0$. Since in the steady-state, with constant prices, real and nominal interest rate coincide, the lower steady state implies not only a negative real interest rate, but also a negative nominal interest rate, that is obviously economically meaningless. The numerical simulations that we provide below (see Table 1) support this reasoning, yielding always a value less than 1 for $\bar{R}_{1}$. We are confident, therefore, that we can rule out this equilibrium.

From the above analysis it follows that the only case in which the economy converges along a uniquely well defined path to a steady-state with positive debt is when we have three steady states in the region where $r<\tau$ (Fig 5). In this case the second steady-state $\bar{R}_{2}$ is a saddle-path, while the third one $\bar{R}_{3}$ is a source.

It is useful, at this point, to see which cases are likely to emerge for given parameter values, and how the government's choices can affect the outcome. In our simulation exercises on this case, we start from the following benchmark parametrization: $\beta=.9, q=.9$, $\psi=.1, \chi=.05, G=.3, T=.2$ and $\tau=0.25$. Our benchmark case reproduces a situation in which agents are not very myopic and the deviation from Ricardian equivalence is not very high. Also, the utility provided by leisure and real balances is assumed to be small compared to the one provided by consumption. We also assume that one third of the maximum amount of work available in every period is used to produce public goods.

This yields a solution in which the three steady state are in the region $r<\tau$, and a well defined, convergent steady-state exists. The result of the simulations are summarized in Table $1 .^{14}$ Figure 7 was generated in Maple setting the parameters at the benchmark levels, and it confirms the shapes of the loci already illustrated in the theoretical analysis

\footnotetext{
${ }^{14}$ In the benchmark case, the selected steady state implies a value of $r \backsim 16 \%$. It is worth stressing here that, since our model is a very simplified one, our aim here is not to produce realistic estimates of the magnitudes of the variables, but rather to gain some insights on the theoretical properties of the economy.
} 


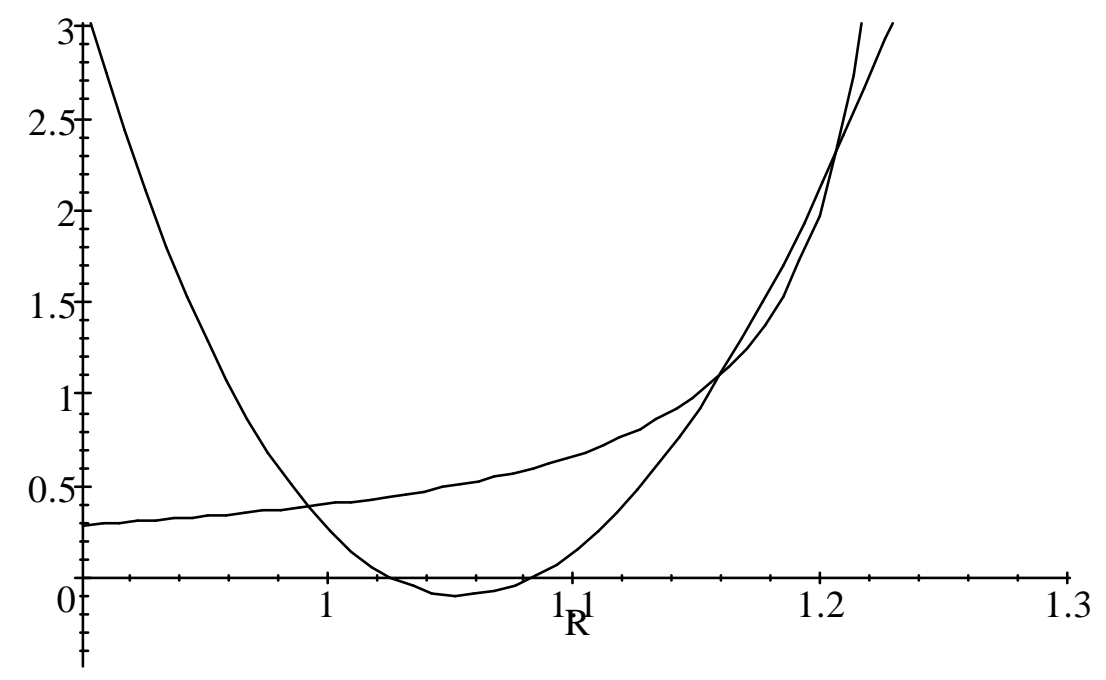

Figure 7:

of Figure 5 .

Table 1. Steady-state values of R and D for different numerical examples (In column

2,3,4 only the parameters reported have been altered with respect to the benchmark case)

\begin{tabular}{|c|c|c|c|}
\hline Benchmark & $q=.85$ & $\tau=.2$ & $\tau=.01$ \\
\hline $\bar{R}_{1}=.992$ & $R_{1}=.987$ & $\bar{R}_{1}=.992$ & $\bar{R}_{1}=.997$ \\
\hline $\bar{R}_{2}=1.16$ & $\bar{R}_{2}$ complex root & $\bar{R}_{2}$ complex root & $\bar{R}_{2}=1.053$ \\
\hline $\bar{R}_{3}=1.207$ & $\bar{R}_{3}$ complex root & $\bar{R}_{3}$ complex root & $\bar{R}_{3}=1.068$ \\
\hline $\bar{D}_{1}=.338$ & $\bar{D}_{1}=.380$ & $\bar{D}_{1}=.482$ & $\bar{D}_{1}=7.815$ \\
\hline $\bar{D}_{2}=1.107$ & $\bar{D}_{2}$ complex root & $\bar{D}_{2}$ complex root & $\bar{D}_{2}=-2.309$ \\
\hline $\bar{D}_{3}=2.324$ & $\bar{D}_{3}$ complex root & $\bar{D}_{3}$ complex root & $\bar{D}_{3}=-1.713$ \\
\hline
\end{tabular}

How do changes in the parameters of the model affect the solutions? Keeping everything else constant, a reduction in $q$ from .9 to .85 gives complex roots for the second and third steady state. Therefore, we are left only with the $\bar{R}_{1}$ solution (See Table 1, column 2). ${ }^{15} \mathrm{~A}$ moderate reduction in $\tau$ (for example, from .25 to .2) has the same effect (Table 1, column 3 ), while if the reduction is drastic (for example, from .25 to .01), we have the case of one steady-state with positive debt and two with negative debt (Table 1, column 4). Notice that in this numerical example we have a saddle-path corresponding to positive debt when

\footnotetext{
${ }^{15} \mathrm{~A}$ similar result emerges if we reduce the discount rate to $\beta=.85$ keeping $q=.9$.
} 
$1+\tau=1.25>\frac{1}{\beta}=1.11$, and a saddle path with negative debt when $\frac{1}{\beta}=1.11>1+\tau=$ 1.01. The eigenvalues for the relevant (positive debt) steady-state have been calculated for this parametrization and are reported in Table 2, confirming that it is a saddle-path.

Table 2. Eigenvalues for the $\left(\bar{R}_{2}, \bar{D}_{2}\right)$ steady-state in the benchmark case

\begin{tabular}{|l|l|}
\hline Steady-state & Eigenvalues \\
\hline $\bar{R}_{2}=1.16 ; \bar{D}_{2}=1.107$ & $\lambda_{1}=.951 ; \lambda_{2}=1.169$ \\
\hline
\end{tabular}

Although the properties of the solutions depend on the vector of all the parameters, the previous analysis suggests that a well-defined saddle-path is more likely to emerge for higher values of $\tau$. In some cases, the tax coefficient on debt needed to ensure a saddle-path with positive debt could be quite high. We therefore suggest that a government that is faced with the dilemma of designing a policy rule that is sustainable and at the same time allows a positive debt steady state could choose an alternative policy rule. In this new rule taxes are a function not only of debt, but also of the divergence between the real interest rate and the taxation coefficient on debt. To clarify our motivations in proposing such a rule, let's consider the following parametrization, in which the deviation from Ricardian equivalence is larger than in the benchmark case: $\beta=.9, q=.685, \psi=.1, \chi=.05$, $G=.3, T=.2$ and $\tau=0.25$. This is a case that produces only one equilibrium (Table 3, column 1). As we know from the previous analysis, this is not a well defined steady state. If the government increases $\tau$ to 0.6 , however, we can have a well defined steady state with a positive level of debt, to which the economy converges along a saddle-path (Table 3, column 2).

A saddle-path with positive debt, however, can also be obtained if the government introduces the alternative rule

$$
\tau_{t}=T+\tau_{1} D_{t}+\tau_{2}\left(r_{t}-\tau_{1}\right)
$$

setting the following tax rates: $T=.25, \tau_{1}=.07, \tau_{2}=.5$ (Table 3 , column 3 ). The eigenvalues corresponding to this steady-state are reported in Table 4.

Table 3. Introduction of a interest-tax rule 


\begin{tabular}{|c|c|c|}
\hline$q=.685$ & $q=.685, \tau=0.6$ & $q=.685 . \tau_{1}=0.7, \tau_{2}=.5$ \\
\hline$R_{1}=.965$ & $\bar{R}_{1}=.958$ & $\bar{R}_{1}=.98$ \\
\hline $\bar{R}_{2}$ complex root & $\bar{R}_{2}=1.25$ & $\bar{R}_{2}=1.17$ \\
\hline $\bar{R}_{3}$ complex root & $\bar{R}_{3}=1.49$ & $\bar{R}_{3}=1.2$ \\
\hline $\bar{D}_{1}=.351$ & $\bar{D}_{1}=.158$ & $\bar{D}_{1}=1.053$ \\
\hline $\bar{D}_{2}$ complex root & $\bar{D}_{2}=.285$ & $\bar{D}_{2}=.0048600$ \\
\hline $\bar{D}_{3}$ complex root & $\bar{D}_{3}=.877$ & $\bar{D}_{3}=.1054469$ \\
\hline
\end{tabular}

Table 4. Eigenvalues for the $\left(\bar{R}_{2}, \bar{D}_{2}\right)$ steady-state in interest-tax rule case

\begin{tabular}{|l|l|}
\hline Steady-state & Eigenvalues \\
\hline $\bar{R}_{2}=1.17 ; \bar{D}_{2}=.0048$ & $\lambda_{1}=-.059 ; \lambda_{2}=1.104$ \\
\hline
\end{tabular}

With this rule we can have a saddle-path with positive level of debt in the region where $r>\tau$. The intuition behind this is quite straightforward. As we said previously, when the real interest rate is bigger than the taxation coefficient on debt, taxes are not growing enough to close the debt if this is positive, so stability can only be achieved for negative levels of debt. In the case of the new rule, we can have a positive debt steady state because, even though the real interest rate is bigger than the taxation coefficient on debt, the additional tax component increases with the real interest rate, preventing the debt from exploding.

From equation (22) it is clear that the new tax rule is taking into account not only the level of the debt (the stock), but also the stream of payments for the government that the existing level of debt is generating. The new taxation component is proportional to the net gains, for the agents, from holding a unit of debt, that is a flow variable. If the $\tau_{1} D_{t}$ component can be assimilated to a wealth-tax (that hits a stock), the $\tau_{2}\left(r_{t}-\tau_{1}\right)$ component can be considered a tax on income from financial capital.

Formally, with the new tax rule the difference equations governing the system are

$$
D_{t+1}=\left(R_{t}-\tau_{1}\right) D_{t}-\tau_{2}\left(R_{t}-1-\tau_{1}\right)+\bar{G}-T
$$

and

$$
R_{t+1}=\frac{1}{\left\{-\left[1-\tau_{1} D_{t}-T-\tau_{2}\left(R_{t}-1-\tau_{1}\right)\right] \frac{(1+\psi)}{(1-\overline{G)}} \frac{(1-q \beta)}{(1+\chi+\psi)} \frac{(1-q)}{q}\right\}+q \beta+\frac{1}{q}-\beta R_{t}}
$$




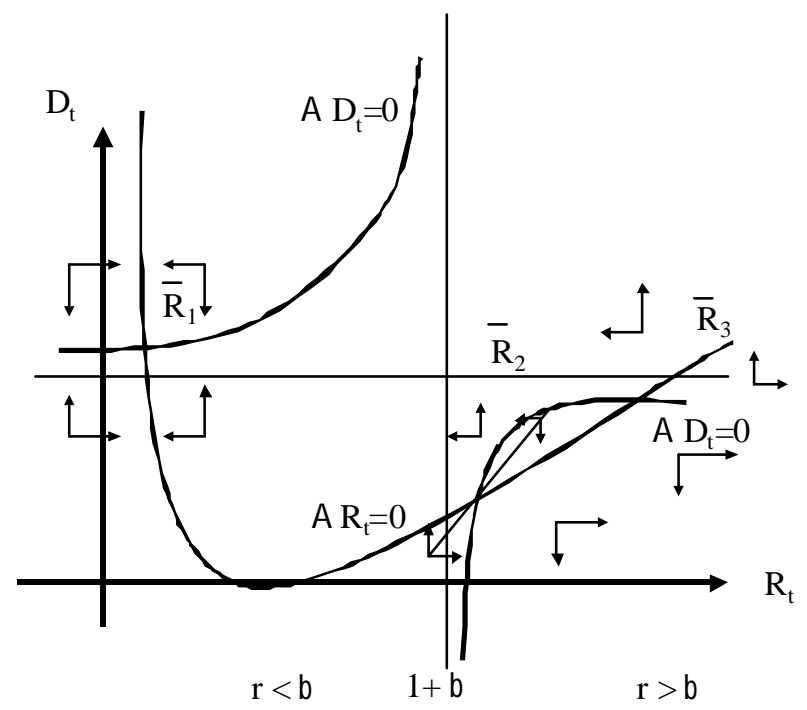

Figure 8:

The $\Delta D_{t}=0$ locus is still the sum of an hyperbola and of a straight line. The line is still upward sloping if the coefficient $\tau_{2}$ is not too big (formally if $\tau_{2}<\frac{\beta}{(1+\psi)}$ $\left.\frac{(1+\chi+\psi)}{(1-q \beta)} \frac{q}{(1-q)}\right)$.

In graphical terms, the introduction of the new component in taxation shifts the horizontal asymptote of the $\Delta D_{t}=0$ locus above zero (to $D=\tau_{2}$ ), and makes possible a saddle-path equilibrium for a positive level of debt in the region where $r>\tau$ (Fig. 8).

In the case of the numerical example that we have provided, the main advantage of using this alternative rule lays in the fact that a fiscal package that implies a much lower tax rate on debt $\left(\tau_{1}=0.7\right)$, a small increase in the lump-sum component in taxes ( $T$ increases from .2 to .25 ) and the introduction of the new tax component (at the rate $\tau_{2}=.5$ ), could be more feasible, from a political point of view, than the alternative of a huge increase of the tax coefficient on debt to .6. A rule like the one that we are proposing would approximate the effects of a rule in which debt inclusive of interest (for example $\tau_{t}=\tau R_{t} D_{t}$ ), but could have the advantage of being more feasible from a political point of view. As we already stressed in the introduction, we do not intend to argue that such a rule would be optimal. Nevertheless, we believe that our analysis could give some useful indication to 
policy makers about a possible way to follow in a situation in which political constraint prevent more drastic measures, like an increase in the taxation of debt (or a reduction in government expenditure). We are not explicitly considering in the model the possibility that agents could refuse to subscribe new public debt when this is being taxed, or when the tax coefficient on this increase drastically, how it would be necessary to achieve stability in the example that we have summarized in Table 4, column 2 . The latter is, however, an example of what we mean by political constraints. Our analysis also gives some warnings about the excessive faith put in the literature and in policy analysis in fiscal "closure" rules since, as we have seen, these can fail to generate a well-defined steady-state for sensible parameters values.

Our analysis is, of course, subject to several caveats. One is the practical working of a rule that makes taxation a function of the real interest rate. It could be problematic, for example, to decide which exact measure of the nominal rates and prices to choose to build the real rate that taxes should target. Furthermore, even if in our model output is fixed, in real economies increases in the real interest rate are likely to be associated with periods of recession. This means that also the alternative rule that we are proposing could be the object of political criticism, since it would be problematic to introduce a rule that automatically increases taxes during a recession. In addition to this, such a rule would give to the monetary authorities a certain degree of (indirect) power on fiscal policy.

\section{Conclusions}

This paper uses a modified version of the Blanchard (1985) model of perpetual youth to investigate the dynamic effects of different fiscal policy rules. The main finding of the paper is that a simple fiscal closure rule, based on a wealth tax, could be insufficient to ensure the existence of a well defined saddle-path equilibrium even when the tax rate exceeds the real interest rate. We suggest that an alternative way of solving this problem could be to add another taxation component, that takes in to account the level of the real interest rate.

Our model is characterized by perfect competition and fully flexible prices. An obvious 
direction in which the work done here could be extended is the introduction of larger departures from neo-classical assumptions. In particular, it could be interesting to consider a version of the model with nominal rigidities and imperfect competition. This would allow an analysis of how the policy rules analyzed in the current paper interact with market imperfections. Studying fiscal rules in a two-country framework would also be relevant. In this direction, a natural extension would be combining the work presented here with the New Open Economy Macroeconomics framework introduced by Obstfeld and Rogoff (1995, 1996). 


\section{References}

[1] Blanchard, O.J., 1985. Debt, deficits and finite horizons. Journal of Political Economy 93, 223-247.

[2] Blanchard, O.J., Chouraqui, J.C., Hagemann, R.P. and Sartor, N., 1990. The Sustainability of Fiscal Policy: New Answers to an Old Question. OECD Economic Studies $15,7-36$.

[3] Blanchard, O.J., and Fischer, S., 1989. Lectures on Macroeconomics. MA: MIT Press.

[4] Christ, C., 1979. On fiscal and monetary policies and the government budget restraint. American Economic Review 69, 526-538

[5] Diamond, P.A, 1965. National debt in a neoclassical growth model. American Economic Review 55, 1126-1150.

[6] Domar, E.D., 1944. The 'Burden of the Debt' and national income. American Economic Review. American Economic Review 34,798-827.

[7] Frenkel and Razin, 1996. Fiscal Policy and Growth in the World Economy, eds. MacMillan.

[8] Heijdra, B., and Ligthart, J., 2000. The dynamic macroeconomic effects of tax policy in an overlapping generations model. Oxford Economic Papers 52, 677-701.

[9] Keynes, J.M., 1923. A Tract on Monetary Reform, reprinted in The Collected Writings of John Maynard Keynes (1971), Macmillan Press, London.

[10] Leith, C., and Wren-Lewis, S., 2000. Interaction between monetary and fiscal policy rules. Economic Journal 110, 93-108.

[11] Mitchell, P.R., Sault, J.E. and Wallis, K.F., 1999. Fiscal policy rules in macroeconomic models: principles and practice. Economic Modelling 17, 171-193. 
[12] Obstfeld, M. and K. Rogoff, 1995. Exchange rate dynamics redux. Journal of Political Economy 103, 624-660.

[13] Obstfeld, M. and K. Rogoff, 1996. Foundations of International Macroeconomics (Ch 10) Cambridge, MA: MIT Press.

[14] Ramsey, Frank P., 1928. A mathematical theory of saving. Economic Journal 38, 54359.

[15] Rankin, N., and Roffia, B., 1999. Maximum Sustainable Government Debt in the Overlapping Generations Model. CEPR DP No. 2076 (February)

[16] Rankin, N., and Scalera, D., 1995). Death and the Keynesian multiplier. Ricerche Economiche 49, 75-87. 